\title{
Ability to Notice Mathematics Specific Phenomena: What Exactly Do Student Teachers Attend to? ${ }^{1}$
}

\author{
Nad'a Vondrová, Jana Žalská \\ Charles University in Prague, Faculty of Education
}

\begin{abstract}
The aim of this paper is to a) shed light on the nature of student teachers' noticing of mathematics specific phenomena as observed in a video recorded lesson and to b) compare this nature for student teachers at the beginning of their master studies at the university and those at its end. Our study is based on a thorough examination of student teachers' written analyses $(n=169)$ of video recorded lessons. We capture the qualities of these in terms of the author-defined notion of mathematics specific (or MS) phenomena by a) matching the students' comments against what we view as important issues in the lessons, and b) developing a framework to further characterise the nature of the observations. Both qualitative and quantitative results corroborate the findings of earlier research on pre-service teachers' lesson analyses in that they pay limited attention to content in the lesson observed. Moreover, it transpires that students tend to notice MS phenomena which are not identified as important by experts and that the demonstrated ability to notice MS phenomena does not show significant differences for students in two distinct stages of a teacher preparation programme.
\end{abstract}

Keywords: ability to notice, pre-service mathematics teachers, mathematics education

DOI: $10.14712 / 23363177.2015 .81$

Observing classroom instruction is a substantial part of mathematics teacher preparation programmes (see, e.g., Star, Strickland, 2008). When observing lessons taught by others (live or on video), pre-service teachers are expected to, among other things, notice those aspects of the lessons that involve mathematical content and how pupils ${ }^{2}$ make sense of the content with the help of the teacher. However, experience from our mathematics education course shows that students often do not respond to noticeable (from our point of view) events specifically pertinent to mathematics teaching and learning. Do the students take away from the video we give them to watch what we would hope for them to take away? Are there any content issues in mathematics lessons which are easier for them to notice than others? Do students in their more advanced stages of the programme really notice more of the important didactic features when observing a lesson? We started looking into this issue more systematically.

The article was supported by research grant GA ČR P407/11/1740.

2 We will use the term students for pre-service teachers and the term pupils for children at primary and secondary schools. 
Noticing is a rapidly growing strand of research (for a comprehensive review, see Sherin, Jacobs, \& Philipp, 2011). Schoenfeld (2011) succinctly summarises why noticing is important: noticing is consequential (what you see and do not see shapes what you do and do not do); noticing is important because it can initiate changes in practices; teachers' noticing is intimately tied to their orientations (including beliefs) and resources (including knowledge); noticing is paramount for adaptive and responsive teaching in which teachers attend closely to pupils' ideas. Teacher noticing is characterised in different ways, most frequently as involving the processes of attending to particular events in an instructional setting and making sense of these events. For example, van Es and Sherin (2002, p. 573, as cited in Sherin \& Star, 2011) propose three aspects of noticing:

(a) identifying what is important or noteworthy about a classroom situation; (b) making connections between the specifics of classroom interactions and the broader principles of teaching and learning they represent; and (c) using what one knows about the context to reason about classroom events.

Some researchers concentrate on the first component of noticing, that is, what is attended to, others look into how it is interpreted, and still others add observers' intended response to what is being noticed to the noticing framework. ${ }^{3}$ Noticing has been studied for different groups of participants and in different settings. We mostly build on studies which deal with (future) mathematics teachers within the context of analysing a mathematics lesson on video and in particular, studies investigating participants' attention to content-specific phenomena.

\subsection{Attention to subject-related content}

The focus of attention has been studied by different measures in studies on noticing. Researchers have investigated the distribution of participants' comments among different aspects of the lesson as well as their quality. For example, van Es and Sherin (2010) coded each comment for Actor (the object of focus), Topic of focus (this category included, among others, Mathematical thinking), Stance, Specificity, and Evidence. Stockero (2008) used categories of Agent, Topic (Mathematical thinking vs. Pedagogical issues), Grounded in evidence or not, and Level (describing, explaining, theorizing). Mathematical content was one of the codes in Kersting et al.'s (2010) study, alongside Student thinking, Suggestions for improvement, and Depth of interpretation.

3 As Sherin (2007) suggests, noticing can be seen in connection to professional vision which has two components (a) noticing or selective attention and (b) knowledge-based reasoning. Janík et al. (2014) suggest that for pre-service teachers, the term pre-professional vision might be more appropriate. 
The above codes refer to both the generic and content-specific pedagogical issues observable in the lesson, whose interplay is at the heart of the quality of the lesson taught. In this study, we will focus on the content-specific issues. Studies have shown that participants do not pay much attention to content issues when observing a video. For example, Carter et al. (1988) claim that inexperienced teachers have difficulty focusing on pupils' (rather than teachers') actions, tend to view a lesson merely as a chronological but disconnected sequence of events, and are not particularly observant about issues of content. Santagata, Zannoni and Stigler (2007) found out that for analyses of both the whole lesson and parts of lessons, students' comments "tended to be about general didactic choices and, when the mathematical content of the lesson was mentioned, only seldom were mathematical ideas used directly to discuss the teacher's actions" (p. 131).

As far as our search in relevant literature suggests, only Mitchell and Marin's (2015) and Kersting et al.'s (2010) studies specifically focus on content. Participants in the former used the Mathematical Quality of Instruction (MQI) framework (Hill et al., 2008) for coding a video of their own teaching and the teaching of others. The authors claim that by using MQI, they purposefully narrowed the participants' focus to "topics most salient to mathematics instruction: mathematics pedagogy and student work with mathematics, rather than classroom management or general pedagogy" (p. 558). The latter study used written video analyses to assess teachers' knowledge and to relate it to their mathematical knowledge for teaching (MKT). An overall correlation between the MKT test and the video analysis score was demonstrated, with the Mathematical content code as the strongest predictor, explaining $37 \%$ of the variance in MKT scores.

Attention to subject content and the way it is present in lessons is indeed an important aspect of teachers' noticing. For example, Star, Lynch and Perova (2011) identified what they call important questions (see below) in all observation categories, with the fewest from classroom environment and most from pedagogical choices made by the teacher, mathematical content addressed in the lesson and teacher-initiated communication. The authors propose that "it is always more important to observe mathematical content carefully than to observe classroom environment carefully" (p. 132). Similarly, Star and Strickland (2008) consider the ways the mathematical content of a lesson is explained and represented as important features worthy of noticing.

\subsection{Important moments in a mathematics lesson}

Most studies on noticing do not distinguish between important and less important events in a mathematics lesson. Star, Lynch and Perova (2011, p. 120) even write:

To be clear, some classroom events are certainly more important than others, and it is critical that preservice teachers be able to attend to and interpret these important events. However, we believe that teachers do not have the ability to notice important 
events (or even to distinguish important from trivial lesson features) until after they have developed the ability to notice (even trivial) classroom features.

The aim of the course described in their study was to activate students' noticing skills of all kinds of events. However, the authors do say that the ultimate goal is for teachers to be able to notice important classroom events and they admit that neither their nor Star and Strickland's (2008) studies showed "whether it is better to focus first on improving teachers' awareness of the full range of (trivial and important) events (as was done here [in their course]) or to focus explicitly on only important events from the outset" (p. 132).

We consider important moments of a mathematics lesson those which are generally accepted to play the key role in pupils' learning of mathematics, that is, the types of tasks that teachers present and the kind of discourse that they orchestrate when implementing the tasks in lessons (Hiebert et al., 2003). Moreover, we put an emphasis on the active role of pupils in developing their knowledge. This means that we deem important the concept of opportunity to learn, defined as the "circumstances that allow students to engage in and spend time on academic tasks such as working on problems, exploring situations and gathering data, listening to explanations, reading texts, or conjecturing and justifying" (Kilpatrick, Swafford, \& Findell, 2001, p. 333). It includes “considerations of students' entry knowledge, the nature and purpose of the tasks and activities, the likelihood of engagement, and so on" and is seen as the single most important predictor of pupils' achievement (Hiebert \& Grouws, 2007, p. 379).

\subsection{Our previous work}

We build on the work mentioned above (and others) by selecting a particular focus for noticing, namely the mathematics specific context of the lesson. As the idea of noticing is based on specific, concrete, data observation, we will use the word phenomenon to refer to an observable situation. By mathematics specific (MS) phenomena we mean such that could be observed, explained, inferred or interpreted in relation to either mathematical or didactic issues pertaining to the teaching or learning of mathematics (as opposed to the teaching and learning of other subjects). ${ }^{4}$ Thus, noticing MS phenomena can be seen as part of professional vision of a teacher of mathematics as opposed to a teacher of other subjects. When noticing MS phenomena and commenting on them, students demonstrate both content and pedagogical content knowledge (Shulman, 1986). The above research studies include noticing MS phenomena in one way or another but their categories do not match ours. For example, our MS phenomena category fully aligns with Star and Strickland's (2008) Mathematical content category but it aligns with their categories Communication and Task only insofar as the phenomenon in question involves some notion of teaching and learning mathematical content.

4 Further clarification of this concept will be provided in sections below. 
The presented study is a continuation of our previous study (Vondrová \& Žalská, 2012), in which we were able to report the results of a detailed examination of 30 students' written analyses of a video recording of one full mathematics lesson. Overall, we confirmed that although the group of participants paid attention to issues of general pedagogy and classroom management, they did not tend to notice and comment on even prominent aspects related to mathematical content, such as a carefully devised series of tasks that the teacher in the video used to introduce new mathematical content, or the mathematics content contained in individual pupil-teacher interaction. The study also raised the question of explicitness - surely, the noticing or not of MS phenomena depends on their "explicitness" in the video. 5 The data also suggested that there may be some differences in noticing MS phenomena between students whose analyses were written in the early stages of their master study and those in later stages. To answer these questions, the present study expands the previous one by an increase of collected data (from 30 to 169 analyses).

\subsection{Research questions}

RQ1. What MS phenomena are noticed by students in a mathematics lesson on video? In particular, are there any types of MS phenomena that are commented on more frequently than others?

RQ2. Do students who are at the end of their master study notice MS phenomena differently from those at its beginning?

For our study, the conception of teacher noticing involves both noticing and sense-making of the above discussed van Es and Sherin's framework. In other words, students provide evidence of noticing by making a comment about the noticed event and it does not suffice that they simply describe an event in the lesson: there must also be some evidence of sense-making (such as interpretation or evaluation). Note that the nature of interpretation and evaluation or their quality are not subject of our study.

\section{Methodology}

Two methodological issues are particularly important to bear in mind. First, the research design is not a longitudinal study of the development of a particular group of students, in a teaching experiment. Rather, we compare two distinct groups of student teachers at different points of their masters degree programme. The second issue concerns research on noticing in general. There is no other way to capture the

5 Studies on noticing generally do not refer to explicitness. The exception is (Blomberg, Stürmer, \& Seidel, 2011) in which the authors rated clips according to "how difficult they were to evaluate, with some clips portraying aspects of teaching and learning more explicitly observable than other clips" (p. 1134). 
82 ability to notice than through records of what students say or write. Thus, we can only believe their comments to be evidence of the ability to notice.

\subsection{Participants and the teacher preparation programme}

Table 1 presents an overview of the 4 semester masters programme for future mathematics teachers at lower and upper secondary schools. An important part of the programme is devoted to observations of classroom instruction. For example, future teachers spend one day a week in a particular school within a so-called clinical semester. They observe lessons and attend a seminar led by a specialist in pedagogy and a specialist in psychology where the different pedagogical and psychological standpoints of the observed lessons are discussed and reflected on. Besides, student teachers spend the total of 8 weeks at (at least) two schools during their teaching practice assignments, which consist of observing lessons taught by mentor teachers and teaching 4 weeks for each of the two subjects they specialise in. They discuss the observations and their teaching with their mentor teacher at the school, without university-sponsored feedback from a mathematics education specialist. ${ }^{6}$

Table 1 Overview of the mathematics teacher preparation programme

\begin{tabular}{|c|c|c|}
\hline $\begin{array}{c}\text { Mathematics education } \\
\text { experience }\end{array}$ & $\begin{array}{l}\text { Time allocated to the } \\
\text { mathematics education course } \\
\text { Number of videos used }\end{array}$ & Other relevant courses \\
\hline $\begin{array}{l}\text { Semester 1: Mathematics } \\
\text { education course } 1\end{array}$ & $\begin{array}{l}12 \times 3 \text { lessons } \\
2 \text { whole lesson videos } \\
9 \text { clips }\end{array}$ & \multirow{6}{*}{$\begin{array}{l}\text { General and school didactics } \\
\text { course }(12 \times 3 \text { lessons) } \\
\text { Pedagogical and school } \\
\text { psychology course }(12 \times 4 \text { lessons) } \\
\text { Clinical semester at a school } \\
\text { (once a week, observations of } \\
\text { lessons, reflective seminars with } \\
\text { a specialist in pedagogy and } \\
\text { a specialist in psychology) } \\
\text { Mathematics courses (geometry, } \\
\text { mathematical analysis, abstract } \\
\text { algebra) }\end{array}$} \\
\hline \multirow{2}{*}{$\begin{array}{l}\text { Semester 2: Mathematics } \\
\text { education course } 2\end{array}$} & $\begin{array}{l}8 \times 4 \text { lessons } \\
2 \text { whole lesson videos } \\
2 \text { clips }\end{array}$ & \\
\hline & $\begin{array}{l}\text { teaching practice ( } 4 \text { weeks at } \\
\text { the primary school) }\end{array}$ & \\
\hline \multirow{2}{*}{$\begin{array}{l}\text { Semester 3: Mathematics } \\
\text { education course } 3\end{array}$} & $\begin{array}{l}8 \times 2 \text { lessons } \\
2 \text { whole lesson videos }\end{array}$ & \\
\hline & $\begin{array}{l}\text { teaching practice ( } 4 \text { weeks at } \\
\text { the secondary school) }\end{array}$ & \\
\hline $\begin{array}{l}\text { Semester } 4 \text { : Course on } \\
\text { the work with talented } \\
\text { pupils in mathematics }\end{array}$ & $11 \times 2$ lessons & \\
\hline
\end{tabular}

6 With the exception of two to four lessons. 
The mathematics education courses are mainly focused on the development of students' pedagogical content knowledge: ${ }^{7}$ the courses start with more general issues such as a theory of concept development process in mathematics, teaching based on the ideas of constructivism, communication patterns in mathematics lessons, etc. They are applied in the rest of the courses when the focus is on the mathematics of lower and upper secondary schools. The course material also includes several tasks with video recordings of mathematics lessons. Table 1 shows how many whole lessons/clips the students are asked to see and comment on in some way. Note that the development of noticing skills is not the main goal of the courses. Rather, the videos are used as a means of illustrating theoretical knowledge and linking theory and practice, a basis for discussion, providing students with more experience, and also making them aware of the complexities of teaching and learning processes.

The participants of the study $(n=169)$ were student teachers - future lower and upper secondary mathematics teachers in their two years of masters studies. We collected their answers at different stages of their programme. Students referred to as DM1 $(n=81)$ participated at the beginning of their first semester, and DM3 students $(n=53)$ in their third or last semesters of the study. Thus, the relevant difference between DM1 and DM3 students is a year of participation in the teacher education programme. The third group of students referred to as DM2 $(n=35)$ participated in the middle of their masters study. Only $10 \%$ of all the participants had some teaching experience as unqualified mathematics teachers at the time of writing the analyses. Most of the participants were in their early- or mid-twenties, the oldest participant was 34 years old. Prior to starting their two-year masters studies, they all had completed a bachelor degree in "mathematics with the focus on education" (mostly at the same university) or an equivalent degree.

\subsection{The video recorded lessons}

In a course for 5 doctoral students ${ }^{8}$ in mathematics education in 2009 , observations and analyses of 10 videotaped lessons from TIMSS 1999 Video Study were carried out. At the end of the course, the students were asked to choose lessons which a) they considered authentic, ${ }^{9}$ that is, showing teaching practices to which they can relate and which are understandable for them, b) concerned subject matter with which student teachers are familiar, c) are self-contained (have a clear introduction and ending, so that the knowledge of the content of the previous lessons is not necessary),

7 Naturally, the mathematics education courses were not taught in the same way in all the years in which we collected data (albeit the course teacher was the same). Their content has undergone changes in terms of compulsory reading, tasks assigned and the set of video recordings used. But the core of the courses remained the same.

8 The students had a master degree in mathematics education and had some teaching experience from lower and/or upper secondary schools. They were in their second or third year of Ph.D. study in mathematics education in which they worked on their own research. They can be considered experts.

9 It has been shown that perceived authenticity of the video material has an impact on reflections (Blomberg, Stürmer, \& Seidel, 2011). 
84 d) are reasonably rich in generic and subject-specific content (Blomberg, Stürmer, \& Seidel, 2011) so as to ensure that they would offer a solid base ${ }^{10}$ for our study (there is quite a number of events to be noticed), e) depict MS aspects of teaching in a clear way, that is, they are easily observable. From the five lessons selected by the doctoral students, we chose three which do not present any particular topic covered in depth by one mathematics education course or another as we did not want to use the lessons as a direct extension of the students' course session experience.

The selected lessons of Grade 8 classrooms were recorded ${ }^{11}$ in classrooms in two countries (AU04 in Australia, HK01 and HKO4 in Hong Kong). They were all conducted in the English language and given to the students of fline, ${ }^{12}$ with Czech subtitles. Lesson HKO1 is 35 minutes long ( 40 pupils, the topic of square roots), HK04 32 minutes long (42 pupils, the topic of equations that are identities) and AU04 69 minutes long (30 pupils, the topic of ratios).

\subsection{Data (video based task)}

The participants were given an assignment to watch one of the three video recordings (individually, outside class, with the possibility to rewind or pause). They were asked to watch the video and write their reflection on it. They were to write what they "considered important and noteworthy". They were told that there "were no correct or wrong answers" and that they should "feel free to write their honest opinions". There are many aspects which might be attended to in the lesson and as we wanted to see whether the students would choose the MS one, we did not give them any more guidance as to what their reflection should include, nor were there any requirements about the depth and/or detail. There was no other information than the pupils' age and the country of origin regarding the lessons provided for the analysis.

The shortest analyses were as short as ten sentences, the longest ran two pages long. Table 2 gives a summary of the collected data in terms of the number of commented video recordings and the advancement in the teacher preparation programme of the students. The data were collected between 2009 and 2014.

Table 2 Summary of collected data (number of analyses for each group of students and video)

\begin{tabular}{lcccc}
\hline Videos/Course & AU04 & HK01 & HK04 & Total \\
\hline Total all students & $\mathbf{5 4}$ & $\mathbf{5 7}$ & $\mathbf{5 8}$ & $\mathbf{1 6 9}$ \\
\hline Group DM1 & 16 & 33 & 32 & 81 \\
Group DM3 & 24 & 13 & 16 & 53 \\
Group DM2 & 14 & 11 & 10 & 35 \\
\hline
\end{tabular}

10 The Australian lesson has already been shown to serve our needs in our previous study (Vondrová \& Žalská, 2012).

11 See http://www.timssvideo.com/videos/mathematics/Australia and http://www.timssvideo .com/videos/mathematics/Hong\%20Kong.

12 That means that the students did not read the comments provided for the lessons by their teachers and researchers on the web. 


\subsection{Data analysis}

The analysis of the students' responses was done by first selecting units of analysis that were MS related. Each unit contained a sentence, sometimes a few sentences (not necessarily consecutive in the written analysis structure) that commented on the same MS issue. Then a coding system was applied to these units of analysis. Recall that in order to be assigned a code, the comments had to have MS content and go beyond the cognitive level of description.

The coding system consisted of two subsystems described in the following sections: one coding for the expert-identified MS phenomena and one coding for more general MS categories.

\section{Expert analyses in research on noticing}

Using an expert analysis of a lesson as the guiding framework for data analysis is not unusual in research on teachers' noticing. For example, Star, Lynch and Perova (2011) created an expert analysis of videos whose results were important questions: "Questions that both raters independently scored as assessing important features of each lesson were classified as important questions. All other questions were classified as other." (p. 129) The expert analysis was used as a measure for assessing the participants' ability to notice. In the study of Blomberg, Stürmer and Seidel (2011), experts prepared items for rating all video clips together with an expert norm value system. Participants' responses were compared and assigned a value of either 1 (match with the expert norm) or 0 (no match with the expert norm). Star and Strickland's (2008) validation of measures (which they wanted to use to assess students' ability to notice) consisted of making a set of features of the lessons to be noticed and then comparing them against the video analysis made by six experienced mathematics teachers. Before using their expert analysis with their study participants, they eliminated items for which only two or fewer teachers provided a correct answer. Finally, Mitchell and Marin (2015) coded each lesson used in video club sessions by the MQI coding and calculated the percent alignment between participants' scores and the master rater scores.

\section{Important phenomena (expert MS phenomena)}

Of course, determining what is noteworthy in a lesson from the point of view of mathematics teaching depends on one's image of what is actually important in teaching. We considered noteworthy events in which the teacher introduced and developed pupils' understanding of a concept or algorithm, in which he/she reacted to pupils' questions and errors, or in which a pupil showed a sign of (mis)understanding the concept/algorithm, etc. (see section 1.2).

A coding system based on an expert analysis of the three lessons in question was developed. Two authors of the paper (a mathematics teacher educator and a doctoral student in mathematics education with ample experience with lesson analysis) and a doctoral student who had taken part in the course described above assessed 
86 the videos independently and then met to discuss and agree on the set of MS phenomena that were particular to each lesson. The agreement of three experts thus served as a validating tool.

The set of MS phenomena was selected based on their observability and relevance to the notion of noteworthy events shared by the coders. Interestingly, for each lesson there was the same number (7) of observable expert MS phenomena on which the experts agreed (see Table 3). The description of all of them is beyond the scope of this paper. One example is the code "Challenge?" which was used for students' comments that indicate that the teacher in lesson HK01 poses a problem that she presents as "challenging". However, she supplies three possible solutions for pupils to choose from, thus modifying the problem and reducing it to a cognitively lower task. An example of the unit of analysis assigned this code is: "I would not give pupils the solution choices, e.g., why did she write the choices for $J(-4)(=2,=-2$ or no solution) on the blackboard? It seems to me that pupils would have been able to find the solution without this help. At least they could have tried." Some other examples of expert MS phenomena are in section 3.

The students' written reflections were coded for all 7 expert MS phenomena pertaining to each lesson. As stated above, the unit of analysis were comments on the same issue - it could be one sentence or several sentences. If the student returned to the same issue several times in the written reflection, it was only coded once. The coding for the expert MS phenomena was binary (present or not) for each MS phenomenon, without evaluating the quality of the relevant comments. We did not distinguish whether the student's comment was interpretative or evaluative either.

\section{Characterizing MS comments}

After coding several written reflections for expert MS phenomena, we noticed that the students also commented on phenomena that were not part of the expert analysis but that were MS related. Thus, we coded the data in an inductive way, too - each time there was a comment which clearly was about a MS phenomenon, went beyond describing and was not included among expert phenomena, we assigned it a new code with a suitable name. We then organised the codes in the following system of categories:

Didactic Error: Content pedagogical (didactic) error (perceived as such by the student). The student is critical of the decision the teacher made. For example: "Finally the teacher repeats again that there can be two answers, i.e., there exist two [square] roots, but in my opinion, the teacher unnecessarily confuses things by using the minus sign." (HK01)

Didactic Alternative: ${ }^{13}$ The student offers, whether as a complement to a criticism (Didactic Error) or not, an alternative action to be taken by the teacher. For example, "She should have left the [erroneous] record on the blackboard and use

13 This category has a unique characteristic in that its phenomena are not observable in themselves, in other words, while a didactic error can be noticed, the alternative is, more accurately, provided or imagined. However, it has its place in our framework for noticing MS phenomena in that the comments that belong to this category are based on observed facts and their interpretation. 
it to show what usually causes doubts, she should have explained better why she requires pupils to use the form $a^{2}=9$ again, the explanation could have even been made by writing the condition next to it, that is, that we solve the equation for $a<0$." (HK01) We did not assign this code to comments semantically implying an alternative such as "She shouldn't have ...", "It was confusing that ...", etc. unless they include further elaboration.

Teacher's Mathematical Error: Mathematical error or imprecision of the teacher. The student criticises the teacher's conceptual, notational and computational errors or imprecise language. An example is: "However, he then says that for equations, pupils can have one or two solutions and the identities can have infinitely many solutions." (HK04)

Task Choice: Choice of a particular mathematical task or a sequence of tasks overall. For example: "The problems are logically sequenced, they are understandable and clear to pupils, and they gradually move into problems that are stated in a more general way." (HK01)

Task Analysis: Specific observation about or a deeper analysis of a task (apart from its selection by the teacher). For example: "When first introducing the pupils to the square root symbol, the teacher uses the same numbers as they used in the previous problem. I find that quite [effective]." (HK01)

Pupil Commentary: Commentary of a pupil's (or pupils') MS action. For example: "It's possible that the pupil who offered 2 as an answer [...] probably understood that the equal division should be done on the 12 cubes, where there are more possibilities, but if the ratio is to be of two numbers, I can think of two equal piles." (AU04)

Teacher's Reaction: Teacher's response (reaction) to a particular pupil's MS answer/question, etc. For example, comments such as: "Mark stated an imprecise answer. The teacher transformed his sentence instead of explaining the error and letting him try to [restate the sentence] himself." (AU04)

Other: This category was used for miscellaneous MS comments, most of them referring to some theoretical knowledge from mathematics education. For example: "This step from a concrete example to a general concept requires a certain abstraction shift in pupils' minds." (AU04)

One unit of analysis could be coded for more than one category (typically, a didactic error was accompanied by a suggested alternative). As with coding for expert MS phenomena, we did not distinguish interpretative and evaluative comments and did not evaluate the depth of interpretation. While each expert MS phenomenon code could be used in the same written analysis at most once, the code for the general categories could appear in the same analysis several times (for example, the student commented on several didactic errors of the teacher).

Finally, all the identified expert MS phenomena were assigned one ${ }^{14}$ of the general categories (for example, the above described expert-identified MS phenomenon

14 Two in case of one expert-identified phenomenon for AU04 coded "M \& Ms" in which at the end of the lesson, the teacher introduced a task which was not connected to the rest of the lesson in any obvious way; it belongs into two general categories, Task Choice and Didactic Error. 
88 coded as "Challenge?" was assigned category Didactic Error). Thus, units of analysis had zero codes (they did not include MS aspect), one code (they included MS aspect but were not among expert phenomena), two codes (they included MS aspect and were among expert phenomena) or three codes (see footnote 14).

To ensure both reliability and validity, a coding manual was gradually developed by the two authors, with detailed descriptors of the codes. The coders coded independently, checked their code assignments for consistency and then repeatedly met and discussed discrepancies until a 100\% agreement was reached.

When looking for the answer to RQ1, all 169 students' analyses were taken into account. The comparison framed in RQ2 is pertinent to the difference between DM1 and DM3 groups only.

\section{Results}

\section{RQ1. Noticing MS phenomena in general and the nature of this noticing}

To give the reader an idea of how frequently students mentioned MS phenomena in general, we looked at the frequencies of comments about MS phenomena in all written analyses $(M=5.79 ; S D=4.51)$. Figure 1 shows that there were 10 analyses (5.9\%) that had no comment pertaining specifically to the teaching and learning of mathematics, ${ }^{15}$ the median value was 5 comments. The maximum number of comments was 26 (given by one student).

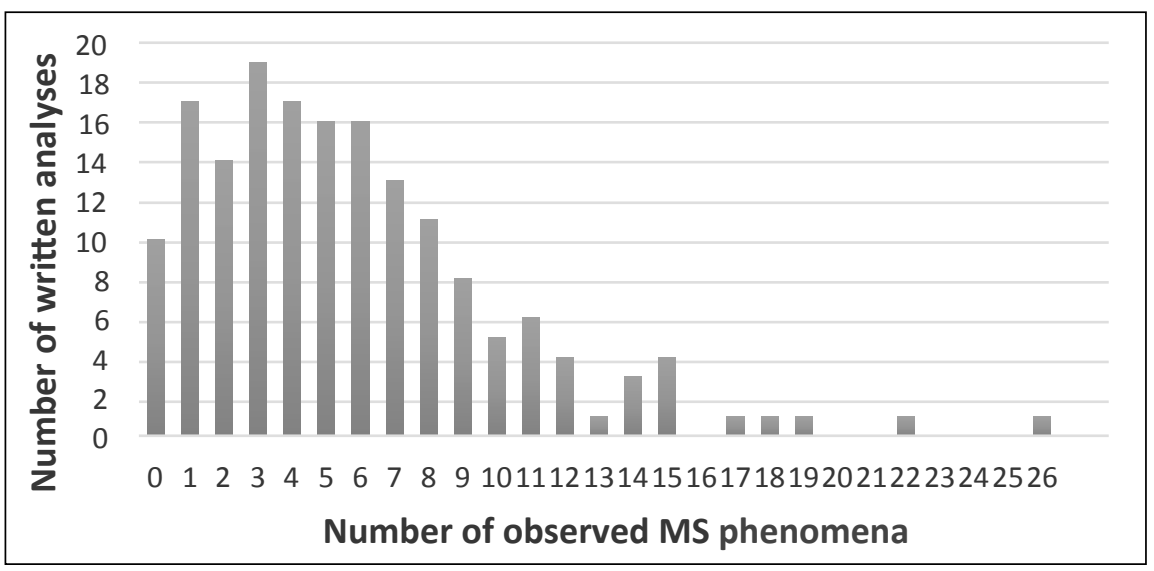

Figure 1 Frequency of observed MS phenomena in all written analyses $(n=169)$

15 That is, these analyses were general or focused on pedagogical and management matters. 
Next, we looked at the type of phenomena the students' attention was drawn to. How much did the students notice the expert identified phenomena overall? Figure 2 shows the number of written analyses with various frequencies. Bearing in mind that each video contained 7 observable, expert-identified MS phenomena, the frequencies $(M=2.08 ; S D=1.59)$ are fairly low, with the median value of just 2 (in fact, over two thirds of the students commented on two or fewer expert MS phenomena). Unsurprisingly, the ratio of students' observed expert phenomena to the expert phenomena in each lesson was fairly low $(M=0.30 ; S D=0.23$ ) (see also Figure 6).

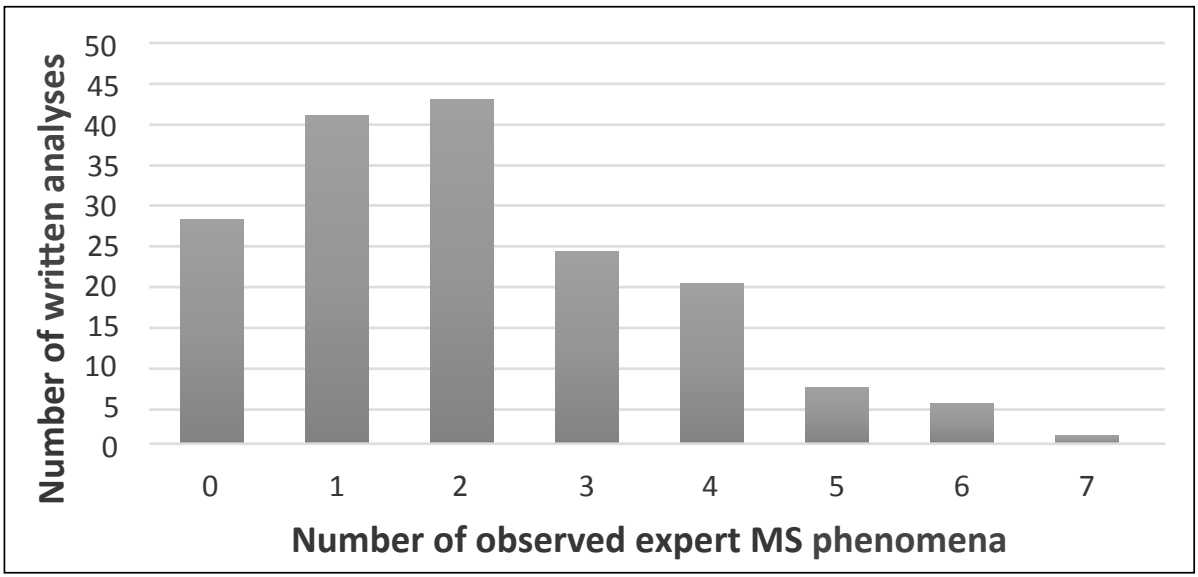

Figure 2 Frequency of observed expert MS phenomena in all written analyses $(n=169)$

To look further into the nature of mentioned expert MS phenomena, we will compare the frequency of comments on all 21 expert MS phenomena. Table 3 depicts the ranks of the expert MS phenomena in connection to the lesson which they concern and to the general category which they belong to. We can see that the expert MS phenomena were mostly commented on in the lesson AU04, where all of them were noticed by no less than a third of the students. We can interpret this in various ways. This lesson has the least resemblance with a traditional Czech classroom and the activities and didactic tools ${ }^{16}$ truly stand out, as well as the didactically problematic ending of the lesson (rank 9 in Table 3) with an activity that seems to be conceptually disconnected from the lesson 17 (the above " $M$ \& $M$ s" code). The length of the lesson may have also influenced the quality of the reflections, if for no other reason than that some of the phenomena simply took place over a longer period of time and therefore were easier to notice.

On the other hand, the phenomena ranking 18 to 20 concern the cognitive level of the teacher's questions which was quite low in both of the lessons, including the

16 For example, the comments about the use of manipulatives in the lesson - rank 1 in Table 3, and about the incorporation of a pupil problem posing activity in the lesson - rank 2 .

17 Something that is not customary in a 45 minute traditional lesson in the Czech Republic. 
90 appearance of funnelling (Wood, 1998). The least noticed phenomenon (rank 21) regarded a teacher's repeated imprecise use of the 'infinitely many' for the number of solutions of a linear equation which is an identity in HKO4.

Table 3 Frequencies of comments about expert MS phenomena and their ranks

\begin{tabular}{|c|c|c|c|c|c|c|c|}
\hline Rank & Lesson & $\%$ observed & Category & Rank & Lesson & $\%$ observed & Category \\
\hline 1 & AU04 & 72.2 & Other & 11 & HK04 & 31.0 & Task Choice \\
\hline 2 & AU04 & 50.0 & Task Choice & 12 & HK04 & 29.3 & Other \\
\hline 3 & HKO4 & 46.6 & $\begin{array}{c}\text { Pupil } \\
\text { Commentary }\end{array}$ & 13 & HK01 & 28.1 & Pupil Commentary \\
\hline 4 & AU04 & 42.6 & Other & 14 & HK01 & 26.3 & Didactic Error \\
\hline 5 & HK01 & 38.6 & Task Choice & 15 & HK04 & 20.7 & Task Choice \\
\hline 6 & AU04 & 37.0 & $\begin{array}{c}\text { Pupil } \\
\text { Commentary }\end{array}$ & 16 & HK01 & 17.5 & Teacher's Reaction \\
\hline 7 & AU04 & 37.0 & Other & 17 & HK01 & 17.5 & Didactic Error \\
\hline 8 & HK01 & 36.8 & Other & 18 & HK04 & 12.1 & Didactic Error \\
\hline 9 & AU04 & 33.3 & $\begin{array}{c}\text { Didactic } \\
\text { Error, } \\
\text { Task Choice }\end{array}$ & 19 & HK01 & 8.8 & Didactic Error \\
\hline \multirow[t]{2}{*}{10} & AU04 & 33.3 & Task Choice & 20 & HK04 & 8.6 & Didactic Error \\
\hline & & & & 21 & HKO4 & 3.4 & Teacher's Error \\
\hline
\end{tabular}

Finally, we characterized the nature of the comments in relation to the general categories. We found the average number of comments per student and category. Naturally, the videos contained different opportunities for comments pertaining to one category or another. We standardized the number of expert codes by the number of students to give a sense of comparison. Figure 3 shows how much more (or less) students commented on phenomena belonging to one kind of category. For example, the figure shows that students commented less on pupils' thinking (category Pupil Commentary; 0.21) than the experts, across the videos. The students tended more to comment on a teacher's didactic error (Didactic Error; 2.29) than on phenomena from all the other categories, and the least commented on category was Teacher's Mathematical Error $(0.16)^{18}$. Students significantly lagged behind the expert analyses in commenting on task choice (Task Choice; 1.02).

Of course, the standardization is really only giving a very rough guideline because there were other opportunities, apart from the expert phenomena, that the students found noteworthy. We confirmed (as already suggested by the low frequency of observed expert phenomena) that the students' and the expert comments in one category were more often than not concerning different phenomena. In fact, on

18 Only 22 students $(13 \%)$ commented on one or more mathematical errors of the teacher. 
average, $56 \%$ of the students' MS related comments were about phenomena other than those identified in the expert analyses. The box-and-whiskers graph on the right in Figure 7 depicts the distribution of the ratio of observed non-expert MS phenomena to all observed $M S$ phenomena $(M=0.58 ; S D=0.30)$ for all students.

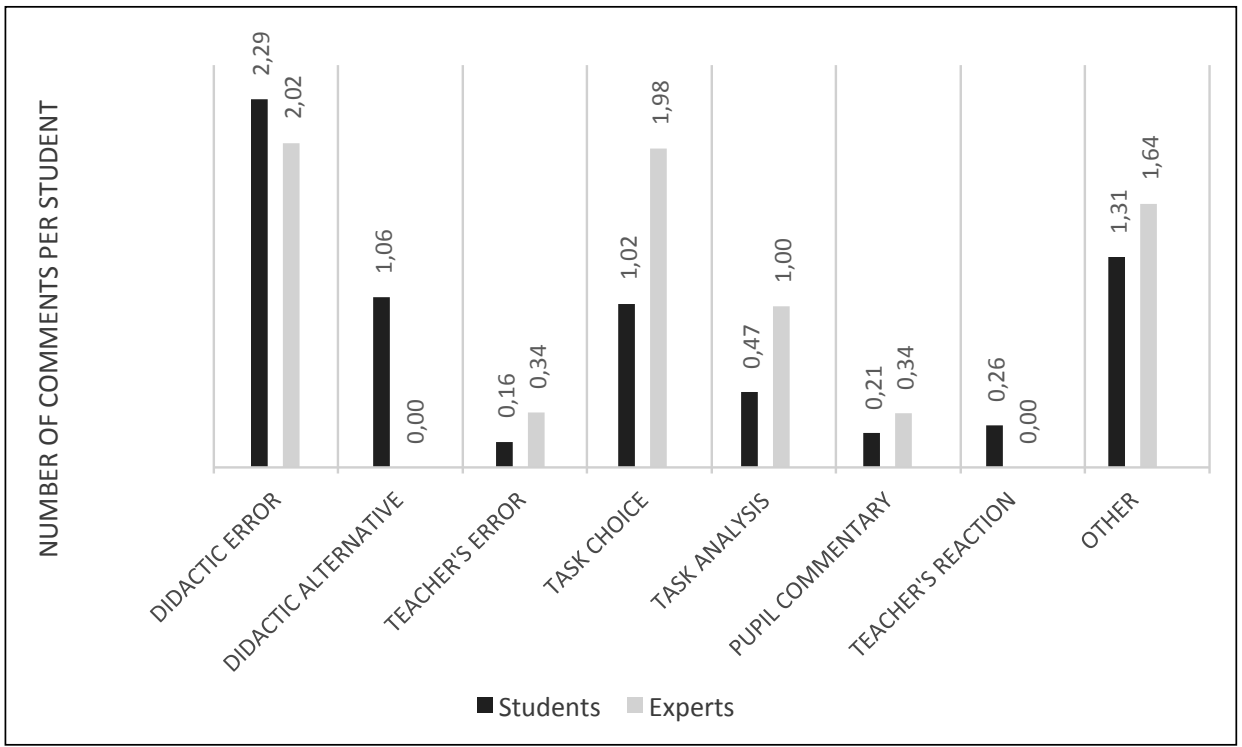

Figure 3 Frequency of comments in categories: students and experts ${ }^{19}$

The general category of Didactic Error ranked among the lowest in Table 3 (that is, the students commented the least on expert MS phenomena that were coded as didactic errors). Yet, Figure 3 shows that the category was the most popular, even exceeding the expert frequencies (unlike all the other categories). Apparently, the students were commenting on didactic errors that were not seen as important by experts (or were not seen as errors at all), and tended to not notice or to pass without commentary a teacher's decisions that were pointed out as lost teaching and learning opportunities by the expert analyses.

\section{RQ2. Differences in noticing between the DM1 and DM3 groups}

To identify whether there may be any differences between students at the beginning and end of their masters studies, we compared data for groups DM1 and DM3. It is important to keep in mind that we do not follow the development of one group of students. Technically speaking, our data allow us to compare two populations, each consisting of students with the same characteristic: the number of semesters they had attended the masters programme.

19 The expert analysis did not, by nature, include any didactic alternatives. 
We first looked at the presence of all MS comments in the students' written analyses. To find out whether there is a significant difference between groups DM1 and DM3, a Wilcoxon rank sum test was performed on the total of MS related comments written by a student. The test indicates that there is a difference $(\alpha=.05)$ between groups DM1 and DM3 $(U=1585.5 ; p=.010 ; r=.22)$, however, the effect size is small. Figure 4 highlights the distribution of MS comment count per student for the group $\operatorname{DM1}(M=5.3 ; S D=4.42)$ and the group DM3 $(M=7.00 ; S D=4.48)$.

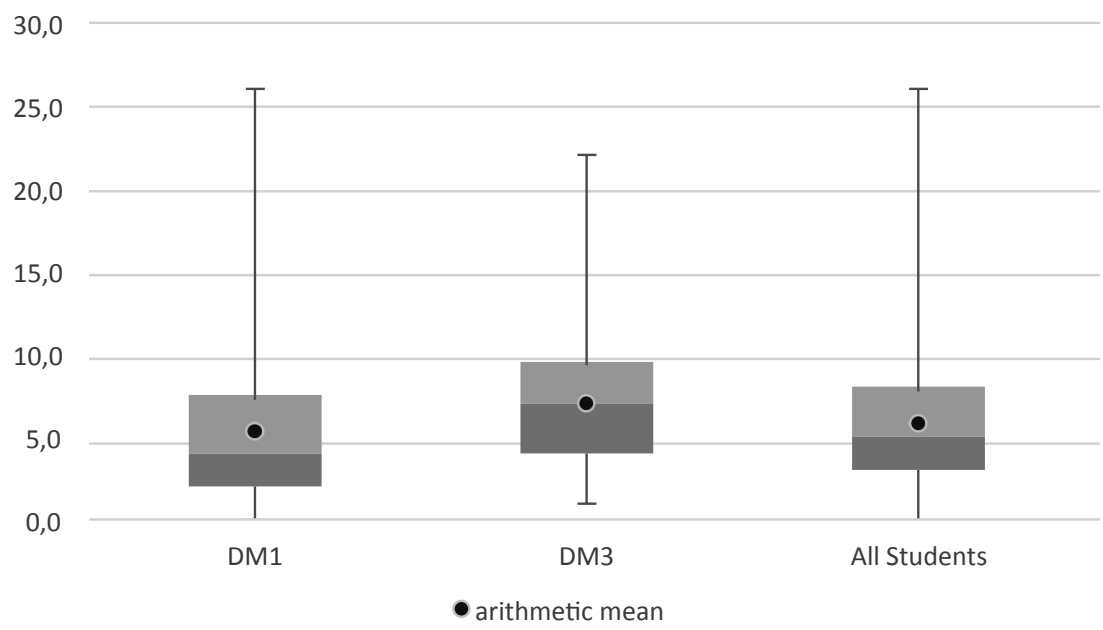

Figure 4 Distribution of MS comment count per student

Next, to partially avoid the influence of the particular video content ${ }^{20}$, we standardized the frequencies per general category by the maximum value for each category and video. Table 4 shows the maximum values for each lesson and category. For example, number 4 in the "Task Choice/AU04" cell means that no student mentioned a phenomenon related to task choice more than in four instances (and at least one student did so in exactly four cases) when commenting on lesson AU04. In principle, we can presume that there were four opportunities on which a student could comment on Task Choice category in AU04. Surely, such a number of opportunities cannot be objectively arrived at, however, this provides a plausible kind of measure. The ratio of the student's actual number of observations made about that particular category and the maximum value tells us about his/her ability to notice the particular category.

20 The number of MS related comments of a student for a particular video recorded lesson was calculated to show whether any video stimulated a significantly higher (or lower) response in terms of MS comments from students. The values are fairly stable across the lessons: AU04 $(M=7.48$; $S D=5.60)$, HKO1 $(M=6.68 ; S D=5.16)$, HKO4 $(M=6.21 ; S D=5.84)$. Still, we found it prudent to proceed with standardization as described in the text following this footnote, especially given the decisively longer run of lesson AU04. 
Table 4 Maximum numbers of comments on each general category and each lesson

\begin{tabular}{ccccccccc}
\hline $\begin{array}{c}\text { Maximum } \\
\text { value }\end{array}$ & $\begin{array}{c}\text { Didactic } \\
\text { Error }\end{array}$ & $\begin{array}{c}\text { Didactic } \\
\text { Alternative }\end{array}$ & $\begin{array}{c}\text { Teacher's } \\
\text { Mathematical } \\
\text { Error }\end{array}$ & $\begin{array}{c}\text { Task } \\
\text { Choice }\end{array}$ & $\begin{array}{c}\text { Task } \\
\text { Analysis }\end{array}$ & $\begin{array}{c}\text { Pupil } \\
\text { Commentary }\end{array}$ & $\begin{array}{c}\text { Teacher's } \\
\text { Reaction }\end{array}$ & Other \\
\hline AU04 & 12 & 6 & 4 & 4 & 3 & 1 & 3 & 5 \\
HK01 & 9 & 7 & 1 & 3 & 1 & 2 & 3 & 5 \\
HK04 & 11 & 9 & 2 & 2 & 1 & 3 & 2 & 6 \\
\hline
\end{tabular}

Figure 5 shows the differences between categories. In particular, it shows the mean standardized value for each category and group. We can see a noticeable difference in performance of the DM3 group: especially the Pupil Commentary and Other categories stand out. A substantial difference can also be seen for Teacher's Reaction and Task Analysis. The mean value for the count-to-maximum-count ratio for Pupil Commentary is 0.06 for DM1 and 0.23 for DM3. For category Other, the difference is caused by non-expert MS comments (i.e., not the ones included in the expert analysis), the mean value for which was 0.15 for the DM1 and 0.36 for the DM3 group. The nature of these comments is mostly related to instances of using theoretical didactic concepts related to the theory of concept development process in mathematics, something the students repeatedly encountered in their mathematics education

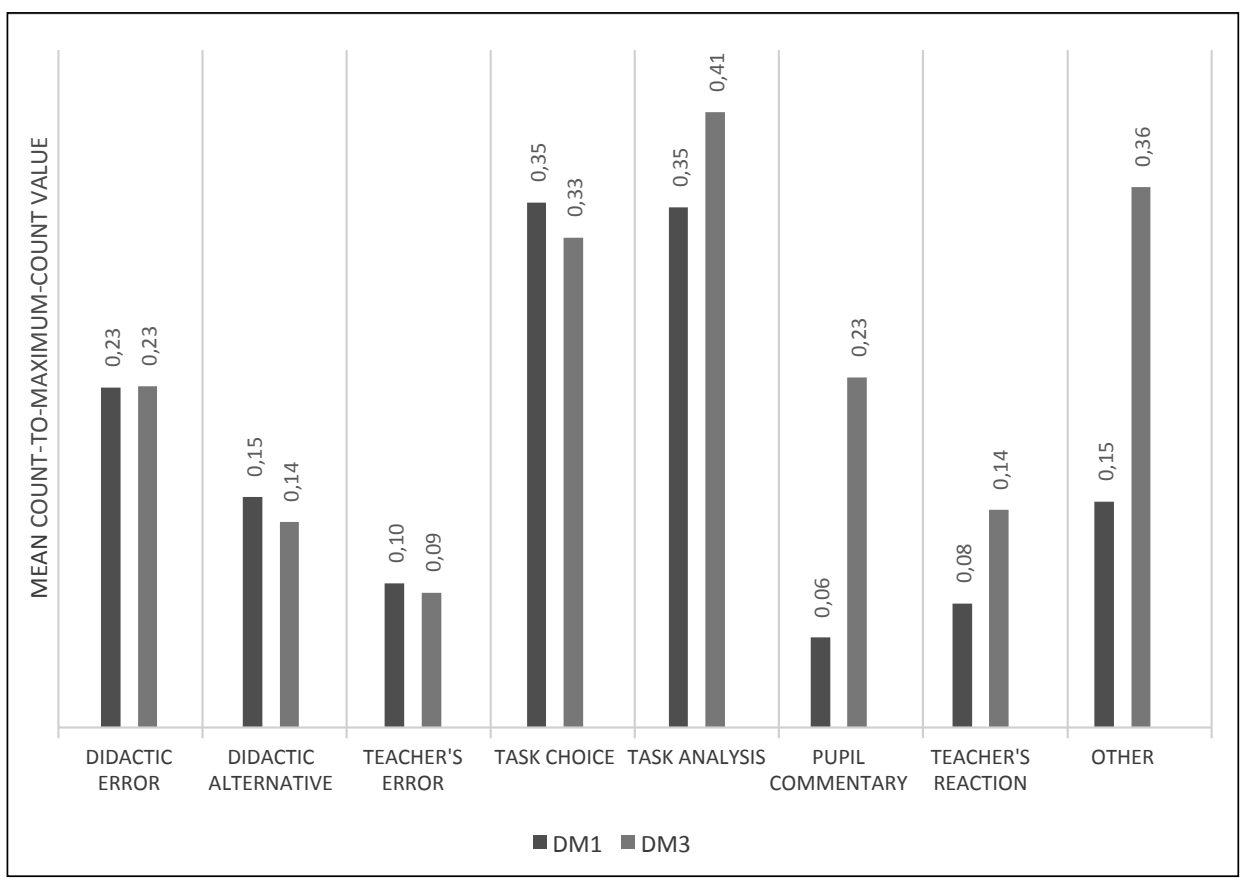

Figure 5 Noticing general MS categories for DM1 and DM3 groups 
94 courses. Note that for category Didactic Error the mean value is about the same (due to rounding) and that DM1 performed slightly higher than DM3 in the number of comments from Didactic Alternative, Teacher's Mathematical Error and Task Choice.

Next, we wanted to look at how much the students commented on phenomena that were deemed important by the expert video analysis. ${ }^{21}$ First, we wanted to see whether there was any difference in terms of students' noticing the expert phenomena. The box-and-whiskers graph in Figure 6 shows how the ratio of the observed expert phenomena to the expert analysis phenomena differed for the two groups. Again, a Wilcoxon rank sum test was performed on the ratios of groups DM1 and DM3 to test for a significant difference of the sample populations. The test shows a difference at $(\alpha=.05)$ between the two groups and, again, the effect size remains small $(U=1708.5 ; p=.042 ; r=.17)$.

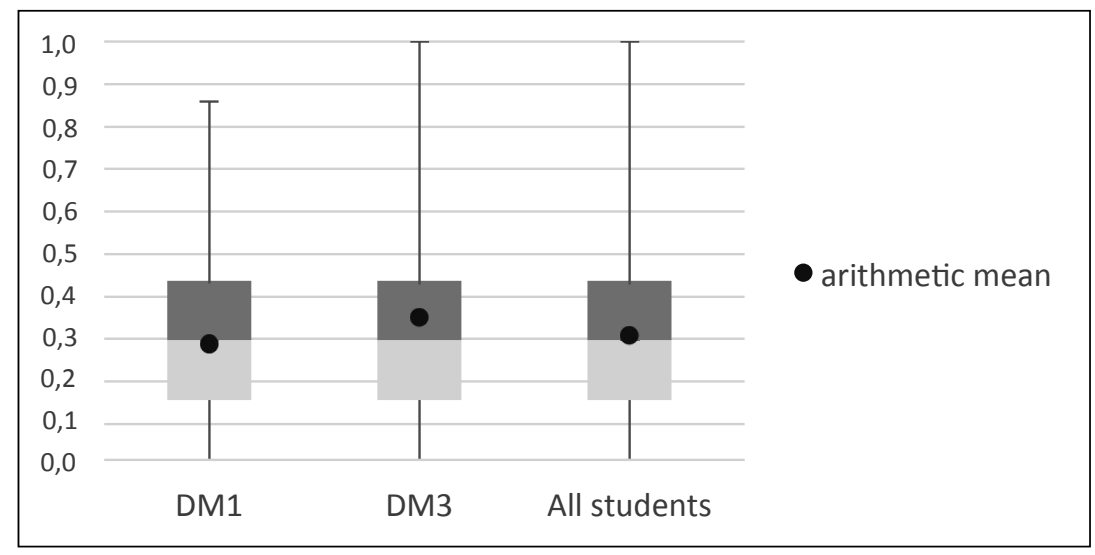

Figure 6 Commenting on expert MS phenomena: the distribution of the ratio "commented on expert MS phenomena to expert MS phenomena" for each group

Next, we computed the ratio "commented on non-expert MS phenomena to total MS phenomena" per student which shows us how often they commented on other than the expert identified MS phenomena. The high values in Figure 7 indicate that the students found many other MS phenomena worth reporting on in their written analyses. The proportion of comments that were related to other than the expert identified observable phenomena is high $\left(M_{D M 1}=0.58 ; S D_{D M 1}=0.30 ; M_{D M 3}=0.59\right.$; $S D_{\mathrm{DM} 3}=0.25$ ).

21 The importance we give to this match is based on the fact that one of the experts was the sole teacher of the mathematics education courses described above in which she emphasised the aspects of teaching deemed important for the success of teaching mathematics. 


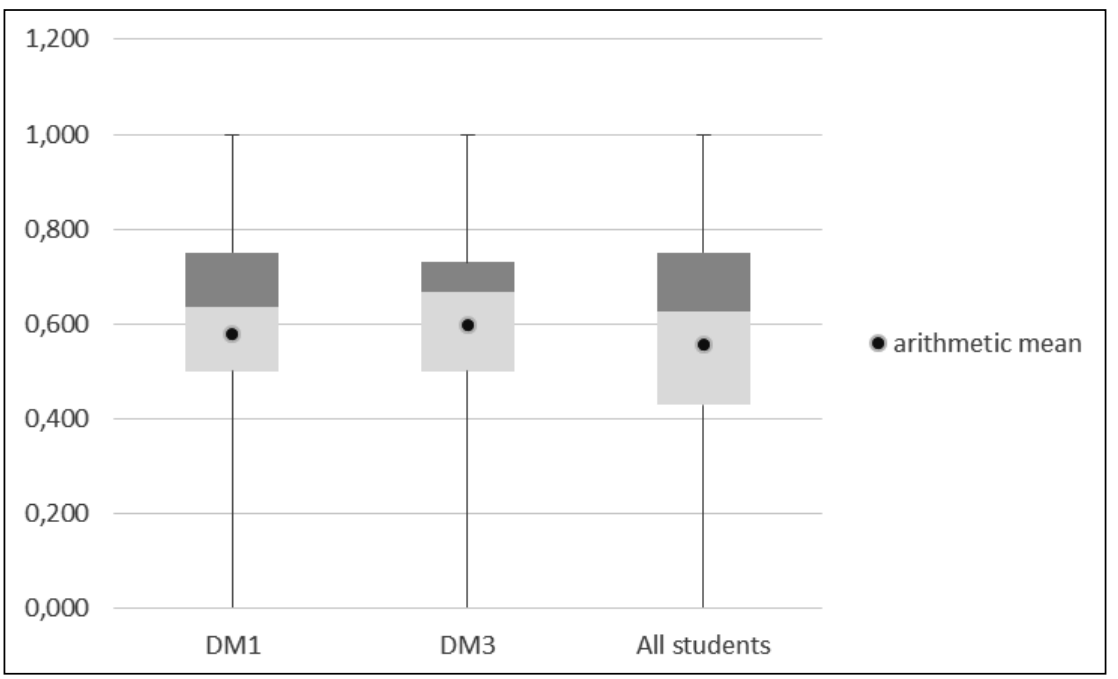

Figure 7 Commenting on non-expert MS phenomena: the distribution of the ratio "commented on non-expert MS phenomena to total MS phenomena" per student

Table 5 depicts percentage of students from the DM1 and DM3 groups commenting on expert MS phenomena. The lightly shaded boxes indicate where DM1 students outperformed DM3 students, the dark boxes mark the opposite situation. Although our data are not extensive enough 22 to give a clear picture, we noticed that the students from DM1 outperformed the DM3 students on the AU04 video by noticing the expert phenomena at a higher rate; while the expert phenomena contained in the other two videos was noticed more often by the students towards the end of their studies. This is an interesting phenomenon but would require further consideration. One interpretation could be that those features of the lesson which appear significant to less experienced DM1 students are deemed as commonplace, or not worth a commentary, by students with more experience in MS analysis and other academic background.

Again, we can see that DM3 students commented more on the expert MS phenomena involving categories Task Choice and Pupil Commentary. As for the earlier mentioned category Didactic Error, the DM3 students were far more likely to describe critically $(53.8 \%$ over $15.2 \%$, rank 14 ) a moment when a teacher introduces a problem as "challenging" but then decides to give her pupils multiple alternatives to choose from, lowering the cognitive task significantly. On the other hand, none of the DM3 students commented on another issue observable in the lesson (rank 17): the fact that the teacher uses exemplary problems and pupils simply follow the same procedure in the following practice activities (while over 30\% of DM1 students commented critically on this feature).

22 From 10 to 22 reflections per group per video, see Table 2. 
96 Table 5 Percentage of students commenting on expert MS phenomena in DM1 and DM3 groups

\begin{tabular}{cccccccccc} 
Rank1 & Lesson & DM1 & DM3 & Category & Rank & Lesson & DM1 & DM3 & Category \\
\hline 1 & AU04 & 81.3 & 66.7 & Other & 11 & HK04 & 34.4 & 25.0 & Task Choice \\
\hline 2 & AU04 & 56.3 & 41.7 & Task Choice & 12 & HK04 & 21.9 & 50.0 & Other \\
\hline 3 & HK04 & 34.4 & $\mathbf{6 8 . 8}$ & $\begin{array}{c}\text { Pupil } \\
\text { Commentary }\end{array}$ & 13 & HK01 & 33.3 & 38.5 & $\begin{array}{c}\text { Pupil } \\
\text { Commentary }\end{array}$ \\
\hline 4 & AU04 & 50.0 & 41.7 & Other & 14 & HK01 & 15.2 & $\mathbf{5 3 . 8}$ & Didactic Error \\
\hline 5 & HK01 & 39.4 & 30.8 & Task Choice & 15 & HK04 & 15.6 & $\mathbf{3 1 . 3}$ & Task Choice \\
\hline 6 & AU04 & 37.5 & 29.2 & $\begin{array}{c}\text { Pupil } \\
\text { Commentary }\end{array}$ & 16 & HK01 & 6.1 & $\mathbf{5 3 . 8}$ & $\begin{array}{c}\text { Teacher's } \\
\text { Reaction }\end{array}$ \\
\hline 7 & AU04 & 56.3 & 33.3 & Other & 17 & HK01 & 30.3 & 00.0 & Didactic Error \\
\hline 8 & HK01 & 36.4 & 38.5 & Other & 18 & HK04 & 12.5 & 12.5 & Didactic Error \\
\hline 9 & AU04 & 50.0 & 16.7 & $\begin{array}{c}\text { Didactic Error, } \\
\text { Task Choice }\end{array}$ & 19 & HK01 & 12.1 & 7.7 & Didactic Error \\
\hline 10 & AU04 & 37.5 & 45.8 & Task Choice & 20 & HK04 & 03.1 & 12.5 & Didactic Error \\
\hline & & & & HK04 & 06.3 & 00.0 & Teacher's \\
& & & & 21 & Error
\end{tabular}

Overall, our data show some tentative differences between the groups in both the number of phenomena noted, and in commenting on the expert-identified features of the lessons, with DM3 students showing slightly better abilities in both aspects (see Figures 4 and 6). The data showed a very large spread, and its distribution is characterised by the lack of normality. While one student commented on all expert phenomena and supplied more MS phenomena related comments than anyone else, there was a total of 10 students who did not report on any MS related phenomena at the required sense-making cognitive level.

The DM3 group seem to pay more attention to individual pupils' mathematical activities and the teacher's reaction to them. However, such comments remain relatively infrequent: for example, based on all the students' comments, there were 3, 3 and 2 opportunities to mention a teacher's reaction (Table 4 ), in each video respectively, and the average number of comments in this category was 0.26 (see Figure 3 ).

Not surprisingly, comments regarding Didactic Error were the most popular ones to be written down. In fact, there was almost no difference between the two compared groups. The quality of these criticisms, though, would require further investigation, as we were able to confirm that most of the time the students tend to comment on errors that fall outside the expert analysis. 


\section{Discussion}

The goal of our study was to investigate to what extent students notice MS phenomena in a video recorded mathematics lesson, whether they pay particular attention to any type of them and whether there is any difference between groups of students at the beginning and end of their masters studies. At the outset, we limited our conception of the ability to notice to consisting of both identifying and sense-making (see Research questions, section 1.4). We can conclude that the participants in our study noticed MS phenomena with great variability. Over $50 \%$ of them noticed mathematics in learning and teaching in five or fewer instances in one video recorded lesson (the number is higher for a longer lesson but not proportionally). When it comes to noticing MS phenomena deemed important by experts, this number is significantly lower (median is 2, expert value is 7). For results of related research see below (Star, Lynch, \& Perova, 2011).

The character of observers' comments depends on the choice of the lesson to be observed. For example, Kersting et al. (2010) point out the effect of selecting clips which call (or do not call) for suggestions for improvement. They conclude that clips with obvious shortcomings may prompt most teachers to make suggestions and thus it is impossible to discriminate among participants in terms of their ability to notice. When looking at our data through these lenses, we can see that the lack of evidence of noticing important MS phenomena in our study is especially true for lessons HK01 and HKO4 that are similar to the traditional Czech classroom in the structure of a lesson, type of tasks and pupil-teacher interaction. This may indicate that the students' experience (as pupils) of traditional classrooms is strongly present in their professional vision, and reflected in their ability to notice phenomena that are important through the lenses of our conception of best practices (which is also the foundation of the teacher preparation programme). This, in turn, could partly explain the fact that students with more teacher preparation programme experience tended to score higher on noticing the expert phenomena in those two lessons - hypothetically, demonstrating a more critical eye for the analysis of the traditional practices.

It did not come as a surprise that phenomena regarding didactic error were the most frequent ones to be written down by our students. In our previous work (Vondrová \& Žalská, 2012) we found that $28 \%$ of the students' comments were of a critical nature (pointing out both didactic and mathematical errors). The percentage was even higher for the bigger sample in this study (34\% for didactic errors and $2 \%$ for a teacher's mathematical insufficiencies). Kersting et al. (2010) propose that suggestions for instructional improvement might be a sign of expertise. In their study, they found that "students of teachers who included suggestions for instructional improvement that they connected to mathematical content showed greater learning gains than did students of teachers who included either general pedagogical suggestions or no suggestions at all” (p. 178). Still, the quality of our students' criticisms should be further investigated. Our study showed that the students tended to comment 
98 on errors that fall outside the expert analysis. Notably, the lack of students' comments concerning issues connected to the teacher's choice of questions and tasks with a low cognitive level seems to align with the lack of critical skills towards the familiar, as hypothesized in the previous paragraph.

Our participants' ability to notice the task as a part of a lesson structure lagged the most behind the expert analysis. The choice of tasks is one of the key features of a successful mathematics lesson (Hiebert et al., 2003). It appears that students' attention should be drawn to this aspect in a more explicit way.

The least noticed category was related to a teacher's mathematical errors and imprecisions. This again confirms our previous results (Vondrová \& Žalská, 2012). Although there were opportunities for noticing a teacher's mathematical errors or misrepresentations in all three videos, only a very small proportion of students (13\%) noticed at least one of these and only two of the 58 students watching the video commented on a moment where the teacher's incorrectness was an important feature of the lesson, possibly hindering pupils' understanding of the content taught. Our data give us no further information regarding this particular feature of the pre-service teacher's (lack of) ability to notice. It is definitely one worth exploring. ${ }^{23}$

Finally, we looked into the differences in the students' ability to notice MS aspect of a lesson at the beginning and towards the end of master studies. Even though we found a difference in the ability between DM1 and DM3 groups, it was rather weak. Students leaving the programme noticed MS phenomena only slightly more often than those entering it. Similarly, in terms of the differences in noticing important moments in a lesson, we did not find any particular difference between DM1 and DM3 groups. Our study was not of the pre-test post-test design, however, we can see tentative corroboration of our results in studies of that design. Even studies which did investigate the development of noticing after a course specifically aimed at the development of noticing mostly report that the gain in the attention to important lesson features was rather weak. For example, in the pre-test of Star, Strickland and Perova's research (2011), the participants showed the same ability to notice important lesson features as other features. By the end of the course, their observation skills continued to be stronger on less important classroom features and they struggled to notice important classroom events. The authors offer two explanations. First, important events may be inherently harder to notice; the most "attention-grabbing features of a lesson (to a novice) may not be those that (in the eyes of an experienced teacher) are most important" (p. 131-132). Second, students may not have developed the ability to distinguish between important and unimportant lesson features. Both explanations are possible and could account for the fact that our students commented to a great extent on MS phenomena other than the expert ones.

23 Mitchell and Marin (2015) focused students' attention to teacher mathematical error or imprecision (conceptual, notation, and computational errors and language imprecisions) within MQI framework. However, they only report their findings in general for all parts of MQI so we cannot compare their results with ours. 
An implication of our study is that if we want to develop our students' ability to notice MS issues in a mathematics lesson, we have to specifically draw their attention to it by suitable tasks. This assumption is confirmed by Mitchell and Marin's (2015) study. They found out that the course specifically aimed at the development of MS aspects of the lesson indeed had a significant influence on students' ability to notice the more salient features of teaching mathematics (mathematical thinking included). Students also improved in their coding MQI accuracy, meaning that they became better at understanding what each code meant and were better able to notice instances in the lesson when there was a need for this code. Among others, the participants were asked in a pre- and post-interviews in an open way "what did you notice?" (this resembles the task we gave our students). By the end of the course, the number of instances of students' unsolicited noticing of MQI codes had doubled, that is, the students spontaneously mentioned MS part of the lesson in twice as many cases.

\section{Limitations and further work}

Our study has some limitations. As stated above, a one-to-one relationship between a noticed phenomenon and one that is chosen for a comment is difficult to establish; we could only work with its conjectured existence. Chances are that a student notices something but for some reason does not record it. Another issue concerns the interpretation of written comments. Some could have been written with a mathematics focus in mind, yet, because they were vague, we did not interpret them as such and did not assign them the MS code. In fact, we "are saying only what their comments are about, from a researcher's point of view, not what they were perceiving" (Sherin \& Star, 2011, p. 76). Next, we assume that the students did their best to do the analysis. However, the context of the task assignment might not have aroused their motivation. We can hypothesise that if it were set as part of their assessment, they could have put more energy into writing deeper analyses. Furthermore, by focusing only on MS comments, we may have painted a rather distorted picture of the students' analyses. The students' analyses included comments on other aspects, general pedagogical ones, psychological, of management etc., which will be dealt with in a different paper (in progress). Finally, "determining what is and is not important is likely to be complex, nuanced, and fundamentally influenced by the perspective of the observer" (Star, Lynch, \& Perova, 2011, p. 132) and thus, we should take into account that our expert analysis might be biased by our professional beliefs and experience.

As stated above, the study is not of a pre-test post-test design and we could only compare two different groups of students at the beginning and end of their university preparation without being able to gauge them as developmental changes. This is addressed in our subsequent research. In autumn 2014, we included a video course within the first mathematics education course and we will look into its effect on the development of students' ability to notice (not only) MS phenomena. 
Another direction of our work goes towards using the coding framework of van Es and Sherin (2010) to capture noticing more generally (and to get more detail about the interpretative nature of students' comments) in order to be able to compare our results with those in the literature using the same framework. This would help us to complement the present study which distorted the image of students' ability to notice by focusing on the subject-specific content only.

\section{References}

Blomberg, G., Stürmer, K., \& Seidel, T. (2011). How pre-service teachers observe teaching on video: Effects of viewers' teaching subjects and the subject of the video. Teaching and Teacher Education, 27(7), 1131-1140.

Carter, K., Cushing, K. S., Sabers, D. S., Stein, P., \& Berliner, D. C. (1988). Expert - novice differences in perceiving and processing visual classroom information. Journal of Teacher Education, 39, 25-31.

Hiebert, J., \& Grouws, D. A. (2007). The effects of classroom mathematics teaching on students' learning. In F. K. Lester (Ed.), Second handbook of research on mathematics teaching and learning (pp. 371-404). The USA: Information Age Publishing.

Hiebert, J., Gallimore, R., Garnier, H., Givvin, K.B., Hollingsworth, H., Jacobs, J., ... Stigler, J. W. (2003). Understanding and improving mathematics teaching: Highlights from the TIMSS 1999 Video Study. Phi Delta Kappan, 84(10), 768-775.

Hill, H. C., Blunk, M., Charalambous, C., Lewis, J., Phelps, G. C., Sleep, L., \& Ball, D. L. (2008). Mathematical knowledge for teaching and the mathematical quality of instruction: An exploratory study. Cognition and Instruction, 26, 430-511.

Janík, T., Minaříková, E., Píšová, M., Kostková, K., Janík, M., \& Hublová, G. (2014). Profesní vidění u učitelů: pokus o zmapování výzkumného pole. Pedagogika, 64(2), 151-176.

Kersting, N. B., Givvin, K. B., Sotelo, F. L., \& Stigler, J. W. (2010). Teachers' analyses of classroom video predict student learning of mathematics: Further explorations of a novel measure of teacher knowledge. Journal of Teacher Education, 61(1/2), 172-181.

Kilpatrick, J., Swafford, J., \& Findell, B. (Eds.) (2001). Adding it up: Helping children learn mathematics. Washington: National Academy Press.

Mitchell, R. N., \& Marin, K. A. (2015). Examining the use of a structured analysis framework to support prospective teacher noticing. Journal of Mathematics Teacher Education, 18(6), 551-575.

Santagata, R., Zannoni, C., \& Stigler, J. W. (2007). The role of lesson analysis in pre-service teacher education: An empirical investigation of teacher learning from a virtual video based field experience. Journal of Mathematics Teacher Education, 10(2), 123-140.

Schoenfeld, A. H. (2011). Noticing matters. A lot. Now what? In M. G. Sherin, V. R. Jacobs, \& R. A. Philipp (Eds.), Mathematics teacher noticing: Seeing through teachers' eyes (pp. 223-238). New York and London: Taylor \& Francis.

Sherin, M. G. (2007). The development of teachers' professional vision in video clubs. In R. Goldman, R. Pea, B. Barron, \& S. J. Derry (Eds.), Video research in the learning sciences (pp. 383-396). London: Lawrence Erlbaum Associates Publishers.

Sherin, M. G., Jacobs, V. R., \& Philipp, R. A. (Eds.) (2011). Mathematics teacher noticing: Seeing through teachers' eyes. New York: Taylor \& Francis.

Sherin, B. \& Star, J. R. (2011). Reflections on the study of teacher noticing. In M. G. Sherin, V. R. Jacobs, \& R. A. Philipp (Eds.), Mathematics teacher noticing: Seeing through teachers' eyes (pp. 66-78). New York: Taylor \& Francis.

Shulman, L. S. (1986). Those who understand: Knowledge growth in teaching. Educational Researcher, 15(2), 4-14. 
Star, J. R., Lynch, K., \& Perova, N. (2011). Using video to improve preservice mathematics teachers' abilities to attend to classroom features: A replication study. In M. G. Sherin, V. R. Jacobs, \& R. A. Philipp (Eds.), Mathematics teacher noticing: Seeing through teachers' eyes (pp. 117-133). New York: Taylor \& Francis.

Star, J., \& Strickland, S. (2008). Learning to observe: Using video to improve preservice mathematics teachers' ability to notice. Journal of Mathematics Teacher Education, 11(2), 107-125.

Stockero, S. L. (2008). Using a video based curriculum to develop a reflective stance in prospective mathematics teachers. Journal of Mathematics Teacher Education, 11(5), 373-394.

van Es, E. A. \& Sherin, M. G. (2002). Learning to notice: Scaffolding new teachers' interpretations of classroom interactions. Paper presented at the annual meeting of the American Educational Research Association, New Orleans, LA.

van Es, E. \& Sherin, M. (2010). The influence of video clubs on teachers' thinking and practice. Journal of Mathematics Teacher Education, 13(2), 155-176.

Vondrová, N. \& Žalská, J. (2012). Do student teachers attend to mathematics specific phenomena when observing mathematics teaching on video? Orbis scholae, 6(2), 85-101.

Wood, T. (1998). Alternative patterns of communication in mathematics classes: Funneling or focusing. In H. Steinbring, M. Bartolini Bussi, \& A. Sierpinska (Eds.), Language and communication in the mathematics classroom (pp. 167-178). Reston: NCTM.

Nad'a Vondrová

Department of Mathematics and Mathematical Education, Faculty of Education, Charles

University in Prague

M. D. Rettigové 4, 11639 Prague, Czech Republic nada.vondrova@pedf.cuni.cz

Jana Žalská

Department of Mathematics and Mathematical Education, Faculty of Education, Charles University in Prague

M. D. Rettigové 4, 11639 Prague, Czech Republic zalska@hotmail.com 